\title{
A major effect quantitative trait locus for whirling disease resistance identified in rainbow trout (Oncorhynchus mykiss)
}

\author{
MR Baerwald ${ }^{1}$, JL Petersen ${ }^{1}$, RP Hedrick ${ }^{2}$, GJ Schisler ${ }^{3}$ and B May ${ }^{1}$ \\ ${ }^{1}$ Genomic Variation Laboratory, Department of Animal Science, University of California, Davis, CA, USA; ${ }^{2}$ Department of Medicine and \\ Epidemiology, School of Veterinary Medicine, University of California Davis, Davis, CA, USA and ${ }^{3}$ Aquatic Research Section, Colorado \\ Division of Wildlife, Ft Collins, CO, USA
}

\begin{abstract}
Whirling disease, caused by the pathogen Myxobolus cerebralis, leads to skeletal deformation, neurological impairment and under certain conditions, mortality of juvenile salmonid fishes. The disease has impacted the propagation and survival of many salmonid species over six continents, with particularly negative consequences for rainbow trout. To assess the genetic basis of whirling disease resistance in rainbow trout, genome-wide mapping was initiated using a large outbred $F_{2}$ rainbow trout family $(n=480)$ and results were confirmed in three additional outbred $\mathrm{F}_{2}$ families ( $n=96$ per family). A single quantitative trait locus (QTL) region on chromosome Omy9 was identified in the
\end{abstract}

large mapping family and confirmed in all additional families. This region explains $50-86 \%$ of the phenotypic variance across families. Therefore, these data establish that a single QTL region is capable of explaining a large percentage of the phenotypic variance contributing to whirling disease resistance. This is the first genetic region discovered that contributes directly to the whirling disease phenotype and the finding moves the field closer to a mechanistic understanding of resistance to this important disease of salmonid fish.

Heredity (2011) 106, 920-926; doi:10.1038/hdy.2010.137; published online 3 November 2010

Keywords: whirling disease; rainbow trout; Myxobolus cerebralis; myxozoan pathogen; disease mapping; QTL

\section{Introduction}

Invasive species are estimated to cost the global economy hundreds of billions of dollars per year (Simpson, 2004) and the negative impact to ecological communities cannot be quantified. The accidental introduction of Myxobolus cerebralis, the parasite causing whirling disease in salmonid fishes, from Europe to countries as far-reaching as the United States, New Zealand and South Africa, is a striking example of how quickly an aquatic invasive species can infiltrate hatcheries and freshwater ecosystems (Bartholomew and Reno, 2002). Whirling disease has negatively impacted survival rates for both hatchery and wild populations of several salmonid species, with rainbow trout (Oncorhynchus mykiss) being particularly susceptible to disease outbreaks (Nehring and Walker, 1996; Hedrick et al., 1999a, b; Vincent, 2002).

A notable exception to the pervasive whirling disease susceptibility observed in O. mykiss is the German hatchery strain known as the Hofer or GR strain (Hedrick et al., 2003). Although a few native US strains have begun to demonstrate modest levels of whirling disease resistance (Wagner et al., 2006), Hofer is currently

Correspondence: Dr MR Baerwald, Genomic Variation Laboratory, Department of Animal Science, University of California, One Shields Avenue, Davis, CA 95616, USA.

E-mail: mrbaerwald@ucdavis.edu

Received 19 May 2010; revised 15 September 2010; accepted 27

September 2010; published online 3 November 2010 the only known strain to display resistance at both consistent and high levels across individuals. Controlled experimental studies comparing Hofer and susceptible laboratory strains of $O$. mykiss, along with their crossed progeny, have revealed that whirling disease resistance has a genetic component (Schisler et al., 2006). To date, genetic studies of the $O$. mykiss whirling disease phenotype have primarily focused on candidate (Severin and El-Matbouli, 2007) and global (Baerwald et al., 2008) gene expression changes in response to infection. These gene expression studies have allowed us to gain insight into potential genes and pathways that may be differentially regulated between resistant and susceptible strains, which is an important step towards understanding host response to infection. However, much remains to be learned about the genetic underpinnings of the disease and gene expression studies alone are not capable of discovering the genetic regions that directly contribute towards host infection outcome.

In this study, we used several outbred $\mathrm{F}_{2} O$. mykiss families to examine the genetic basis of whirling disease resistance. Following the construction of a high-density linkage map, we identified the first significant quantitative trait locus (QTL) contributing to whirling disease infection response in juvenile $O$. mykiss. Juveniles were targeted for pathogen load assessment, as this lifestage suffers the highest mortality rates for whirling disease (Markiw, 1991; MacConnell and Vincent, 2002). The discovery of a large effect QTL for whirling disease resistance has broad implications for improving our general understanding of myxozoan diseases and host/ 
pathogen interactions. Additionally, marker-assisted selection (MAS) for hatchery strains and disease risk assessments for natural populations may contribute to minimizing or eliminating whirling disease outbreaks.

\section{Materials and methods}

\section{O. mykiss strain crosses and $M$. cerebralis challenge}

Females of the Hofer strain (whirling disease resistant) were crossed with males of the Colorado River rainbow trout strain (CRR; whirling disease susceptible) to create $F_{1}$ families. These $F_{1}$ families were then crossed to create four $\mathrm{F}_{2}$ outbred families. All families have no known relationship to each other except families 1 and 2, which are half siblings and share the same $F_{1}$ dam. Data collection took place using 480 progeny in family 1 and 96 progeny each in families 2 to 4 .

The $F_{2}$ families were reared separately in 132.5-1 aquaria with $10-11^{\circ} \mathrm{C}$ single-pass well water until 5 to 6 weeks post-hatch (360-429 degree days). Fish were then exposed to triactinomyxons, the waterborne infectious stages of $M$. cerebralis, at a dose of 1000 triactinomyxons per individual for $1 \mathrm{~h}$ at $15^{\circ} \mathrm{C}$ (Schisler et al., 2006). The fish were held in aquaria receiving $15^{\circ} \mathrm{C}$ well water with a daily ration of commercial trout diet for 60 days after pathogen exposure (1251-1324 degree days). Fish were euthanized with an overdose of benzocaine $\left(500 \mathrm{mg}^{-1}\right)$. Immediately following death, fish weight and length were recorded. Correlations of weight, length, sex and $\log _{2}$-transformed pathogen load (see below) were measured with Pearson coefficients using the software XLSTAT (Addinsoft, 2009). Fish were sexed by using DNA extracted from the gill arch tissue (Puregene Genomic DNA Purification Kit, Qiagen, CA, USA) as the template in PCR reactions containing Y-specific primers for rainbow trout following the conditions detailed in Brunelli et al. (2008).

\section{Pathogen load quantification}

The severity of $M$. cerebralis infection as a measure of the whirling disease phenotype was evaluated by real-time TaqMan PCR using genomic DNA that was extracted from gill arch tissue. The TaqMan procedure was modified from Kelley et al. (2004) to amplify the $18 \mathrm{~S}$ rDNA (M. cerebralis) and insulin growth factor-I (O. mykiss) genes in a single reaction by fluorescently labeling their specific probes with 6-FAM and VIC dyes, respectively. Other than multiplexing and reducing the template DNA to $1 \mu \mathrm{l}$ and the total reaction volume to $12 \mu \mathrm{l}$, all conditions are as described in Kelley et al. (2004). Pathogen loads for each individual represent the number of $M$. cerebralis $18 \mathrm{~S}$ rDNA gene copies per $10^{6}$ rainbow trout cells.

\section{Genotyping}

Originally, 202 microsatellite markers and six amplified fragment length polymorphism primer combinations were used to genotype the family 1 sire and dam to determine the segregating loci. A total of 21 amplified fragment length polymorphism and 122 microsatellite markers (Supplementary Table 1), spanning the genome, were used to genotype all $480 \mathrm{~F}_{2}$ offspring of family 1 , along with their parents. A subset of the microsatellite markers (11-21 per family) was selectively amplified for the three families used for QTL confirmation (families 2-4).

For amplified fragment length polymorphism markers, the protocol described by Vos et al. (1995) was modified as described in Agresti et al. (2000). Further reaction modifications include the use of EcoRI $+\mathrm{A}$ and MseI $+\mathrm{C}$ primers and GoTaq polymerase (Promega, Madison, WI, USA) in the preamplification step and Multiplex PCR Master Mix (Qiagen) in the selective amplification step. The thermal cycling conditions for the selective amplification step were also modified and are as follows: $94{ }^{\circ} \mathrm{C}$ for $15 \mathrm{~min}$ followed by 10 cycles of $94^{\circ} \mathrm{C}$ for $30 \mathrm{~s}, 66^{\circ} \mathrm{C}$ $\left(-1{ }^{\circ} \mathrm{C}\right.$ per cycle) for $1 \mathrm{~min}, 72^{\circ} \mathrm{C}$ for $1 \mathrm{~min}$ followed by 20 cycles of $94{ }^{\circ} \mathrm{C}$ for $30 \mathrm{~s}, 56^{\circ} \mathrm{C}$ for $1 \mathrm{~min}, 72^{\circ} \mathrm{C}$ for $1 \mathrm{~min}$ followed by a final extension at $60^{\circ} \mathrm{C}$ for $20 \mathrm{~min}$. Amplified products were visualized using a 3730xl DNA Analyzer (Applied Biosystems, Foster City, CA, USA) with internal GeneScan 600 LIZ size standards (Applied Biosystems). The run module was modified with a $3 \mathrm{kV}$ injection for $7 \mathrm{~s}$ and fragments were scored using GeneMapper software (Applied Biosystems). Only fragments between 60 and $600 \mathrm{bp}$ that displayed 1:1 segregation ratios in the $F_{2}$ progeny (segregating in only one parent) were included in further analyses. Fragments were named using the three selective bases of the EcoRI primer combined with the three selective bases for the MseI selective primer, followed by the fragment size (bp). The process was performed in triplicate for each parent and five random $\mathrm{F}_{2}$ progeny with any loci scoring inconsistently across replicates being discarded.

Microsatellite markers were chosen based on previously published O. mykiss linkage maps (Danzmann et al., 2005; Guyomard et al., 2006; Rexroad et al., 2008) to provide adequate coverage across all chromosomes. For the $F_{2}$ mapping families, 3-12 microsatellite loci were multiplexed in each reaction using M13, SP6, T7P or T7T universal primer tails (Schuelke, 2000) labeled with 6-FAM, VIC, NED or PET fluorescent dyes (Applied Biosystems). PCR was performed in a $10 \mu \mathrm{l}$ total volume containing: $2 \mu \mathrm{l}$ extracted genomic DNA, $1 \times$ PCR reaction buffer (Roche, Indianapolis, IN, USA), $2.0 \mathrm{mM} \mathrm{MgCl}_{2}$, $0.2 \mathrm{mM}$ of each dNTP, $1 \mu \mathrm{M}$ of each reverse primer, $0.8 \mu \mathrm{M}$ of each forward primer, $0.3-0.7 \mu \mathrm{M}$ of each universal fluorescent tailed primer, and 1.0 U of FastStart Taq DNA polymerase (Roche). Thermal cycler conditions were as follows: $95^{\circ} \mathrm{C}$ for $5 \mathrm{~min}$ followed by five cycles of $94{ }^{\circ} \mathrm{C}$ for $45 \mathrm{sec}, 68^{\circ} \mathrm{C}\left(-2{ }^{\circ} \mathrm{C}\right.$ per cycle $)$ for $5 \mathrm{~min}, 72^{\circ} \mathrm{C}$ for $1 \mathrm{~min}$ followed by five cycles of $94^{\circ} \mathrm{C}$ for $45 \mathrm{sec}, 58^{\circ} \mathrm{C}$ $\left(-2{ }^{\circ} \mathrm{C}\right.$ per cycle) for $2 \mathrm{~min}, 72^{\circ} \mathrm{C}$ for $1 \mathrm{~min}$ followed by 30 cycles of $94{ }^{\circ} \mathrm{C}$ for $45 \mathrm{sec}, 50{ }^{\circ} \mathrm{C}$ for $2 \mathrm{~min}, 72{ }^{\circ} \mathrm{C}$ for $1 \mathrm{~min}$ and ending with a final extension of $72{ }^{\circ} \mathrm{C}$ for $2 \mathrm{~min}$. PCR products were visualized by capillary electrophoresis using a 3730xl DNA Analyzer (Applied Biosystems) and allele sizes were determined using GeneMapper software (Applied Biosystems) with internal GeneScan 600 LIZ size standards (Applied Biosystems).

\section{Map construction and QTL mapping}

Each marker was tested for Mendelian segregation distortion using $\chi^{2}$-analysis with the software program JoinMap 4 (Van Ooijen, 2006). Any marker that significantly deviated from the expected 1:1 ratio was checked for difficulty in allelic scoring and removed from further analysis if deemed unreliable in genotype determination. 
JoinMap 4 assigned markers to map positions using a minimum logarithm of the odds (LOD) threshold of three and a recombination threshold of 0.49 , combined with previous knowledge of marker positions from published maps (Guyomard et al., 2006; Rexroad et al., 2008). The Haldane mapping function was used to convert recombination frequencies to map distances (cM). In addition to a combined parental map, individual maps for each male and female parent were constructed because of large recombination rate differences between rainbow trout sexes (Sakamoto et al., 2000).

QTL analysis was conducted using MapQTL 6 software (Van Ooijen, 2009). As is common for disease resistance traits (Broman, 2003), the whirling disease frequency distribution did not conform to normality with a notable spike in the phenotypic distribution relating to complete resistance. Therefore, the non-parametric Kruskal-Wallis $(\mathrm{K}-\mathrm{W})$ test was initially used to identify markers significantly associated with the disease phenotype for all four mapping families. The phenotypic input was $\log _{2}$-transformed pathogen loads and the significance threshold was set at $P<0.001$. Following $\mathrm{K}-\mathrm{W}$ test, interval mapping (IM) was also conducted using transformed pathogen loads for all families separately and combined into a single data set. The significance threshold for IM was determined with 10000 permutations and a genome-wide threshold of $\alpha=0.05$. The IM analysis was conducted both with and without the use of weight and length as covariates. Significant QTL were graphically visualized using the software MapChart 2.2 (Voorrips, 2002) and a 2-LOD support interval was calculated using the LOD drop-off method (Lander and Botstein, 1989) to obtain $95 \%$ coverage.

Sire and dam allelic segregation patterns of marker BX310634, found to be proximal to the QTL region, were examined to determine the current potential strength of MAS. All individuals with complete resistance (that is, no pathogen load) were compared with the $20 \%$ most susceptible individuals within each family to enable allelic/phenotypic patterns to be identified without confounding intermediate phenotypes.

\section{Results}

\section{Phenotypic trait correlations}

The average length and weight across all $\mathrm{F}_{2}$ progeny were $47 \pm 0.5 \mathrm{~mm}$ and $1.1 \pm 0.3 \mathrm{~g}$, respectively, and were normally distributed. The sex ratio was not significantly different than 1:1 ( $\chi^{2} P$-value $\left.=0.51\right)$. Mortality that could be directly attributed to $M$. cerebralis infection (that is, fish displaying clinical signs of infection) was not observed during this period. Pathogen loads for all four families were not normally distributed (all Shapiro-Wilk $P$-values $<0.001)$ and were $\log _{2}$ transformed to achieve a closer approximation of normality, other than the spike in the distribution relating to disease resistance (Figure 1). Pearson correlation coefficients for weight, length, sex and transformed pathogen load are shown in Table 1. Weight and length were positively correlated with each other and, to a lesser degree, both were negatively correlated with pathogen load. Sex was not correlated with any other trait.

\section{Map construction}

A total of 29 linkage groups were created for family 1 using 122 microsatellite and 21 amplified fragment length polymorphism markers. These groups likely encompass all chromosomes for this cross, though O. mykiss chromosome number is variable across strains ( $2 \mathrm{~N}=58-64)$ (Thorgaard, 1983). Nomenclature for the linkage groups was based on chromosome names using the integrated cytogenetic/linkage map of Phillips et al. (2006). The total map length for this family was $1735 \mathrm{cM}$ and the average intermarker distance was $15.2 \mathrm{cM}$. The number of markers per linkage group ranged from 2 to 19 , with an average of five markers/linkage group. Although not all markers were informative for both

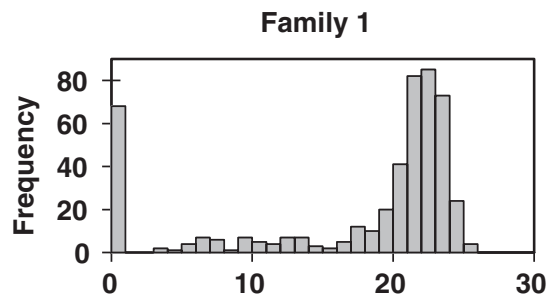

$\log _{2}$ Transformed Pathogen Load

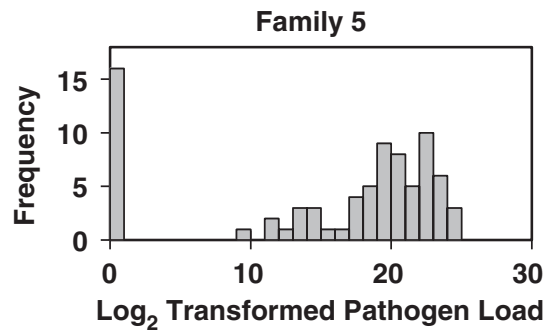

Family 2

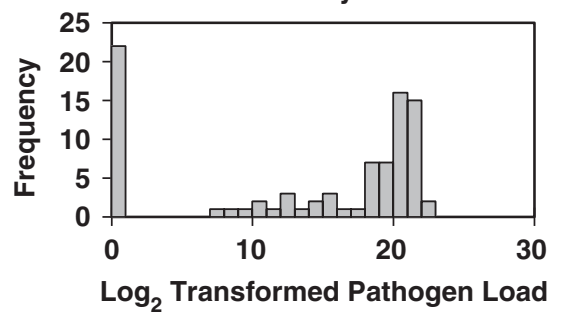

Family 4

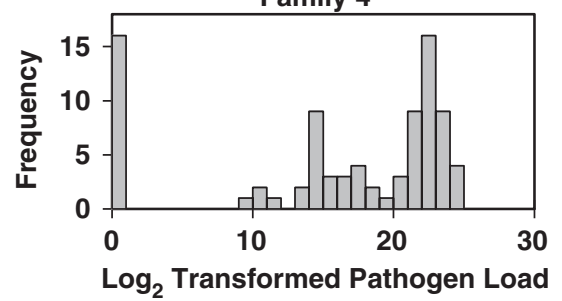

Figure 1 Pathogen load distributions for five rainbow trout families exposed to M. cerebralis. Pathogen loads are the $\log _{2}$-transformed number of $M$. cerebralis $18 \mathrm{~S}$ rDNA gene copies per $10^{6}$ rainbow trout cells. All families demonstrate a bimodal frequency distribution with the majority of individuals either completely resistant (that is, no pathogen load) or very susceptible (that is, very high pathogen load). 
Table 1 Pairwise Pearson correlations among measured traits

\begin{tabular}{lcccc}
\hline Variables & Weight & Length & Pathogen load & Sex \\
\hline Weight & & $\mathbf{0 . 9 0 5}$ & $\mathbf{- 0 . 2 7 7}$ & 0.013 \\
Length & & $\mathbf{- 0 . 3 1 5}$ & 0.000 \\
Pathogen load & & & & 0.053
\end{tabular}

Values in bold are different from 0 with a significance level $\alpha=0.05$.

Table 2 Significant markers for whirling disease resistance using Kruskal-Wallis analysis with four mapping families

\begin{tabular}{lcccc}
\hline Marker & Family 1 & Family 2 & Family 3 & Family 4 \\
\hline OMM1089 & $*$ & NS & $* * *$ & $* * *$ \\
Omy1090UW & $* * *$ & NS & $* * *$ & $* * *$ \\
OMM1701 & $* * *$ & NS & - & - \\
Omy1403INRA & $* * *$ & NS & $* * *$ & NS \\
OMM5126 & - & $*$ & - & $* * *$ \\
OMM1453 & $* * *$ & $*$ & - & - \\
OMM5129 & $* * *$ & - & $* * *$ & - \\
OMM1419 & $* * *$ & $* *$ & - & - \\
BX310634 & $* * *$ & $* * *$ & $* * *$ & $*$ \\
Omy1252INRA & - & $* *$ & - & - \\
Omy1512INRA & - & $* * *$ & - & - \\
BX082639 & - & $* * *$ & - & - \\
aagcta227 & $* * *$ & - & - & - \\
\hline
\end{tabular}

Abbreviations: NS, not significant; - , not informative in family.

$P$-value significance levels: ${ }^{*}<0.05 ;{ }^{* *}<0.001 ;{ }^{* * *}<0.0001$.

parents, in general, recombination was five times greater in the female versus the male parent with total map lengths of 1530 and $629 \mathrm{cM}$, respectively. The 24 markers amplified for one or more of the three confirmation families created a single linkage group for each family with map lengths ranging from 64 to $156 \mathrm{cM}$ depending on the family. Marker map positions for all families can be found in Supplementary Table 1.

\section{QTL analysis of whirling disease resistance}

For family 1, eight markers were significant for disease QTL using $\mathrm{K}-\mathrm{W}$ test, all located on a single linkage group corresponding to chromosome Omy9 (Table 2). All of these markers achieved the highest level of statistical linkage to the disease QTL possible using the MapQTL software $(P<0.0001)$. The three additional mapping families showed consistent results to family 1 (Table 2), with a total of 13 markers significant in one or more families, all positioned on chromosome Omy9. A total of $46 \%(6 / 13)$ of the significant markers were confirmed in two or more families and an additional $31 \%$ (4/13) were informative for only one family, so confirmation across families was not possible.

Interval mapping for family 1 detected a QTL (termed WDRES-9) in the same chromosomal region on Omy9 as the $\mathrm{K}-\mathrm{W}$ non-parametric test. The peak LOD value of 63.1 was substantially higher than the genome-wide LOD significance threshold value of 4.1 determined by permutation testing (Table 3). No other chromosomes contained LOD scores above the significance threshold value, even when using composite IM with automatic marker cofactor selection. Families 2 to 4 all confirmed the family 1 results with peak LOD values ranging from 11.6 to 34.0. Marker BX310634 was proximal to the peak
Table 3 Quantitative trait loci for whirling disease resistance in four rainbow trout mapping families

\begin{tabular}{lcccc}
\hline Family & Peak LOD & Significance threshold & Closest marker & PVE \\
\hline 1 & 63.1 & 4.1 & BX310634 & 49.6 \\
2 & 13.9 & 3.0 & BX310634 & 60.0 \\
3 & 34.0 & 3.1 & BX310634 & 85.9 \\
4 & 11.6 & 2.8 & BX310634 & 54.3 \\
\hline
\end{tabular}

Abbreviation: PVE, percent of phenotypic variance explained. Genome-wide significance threshold $\alpha=0.05$.
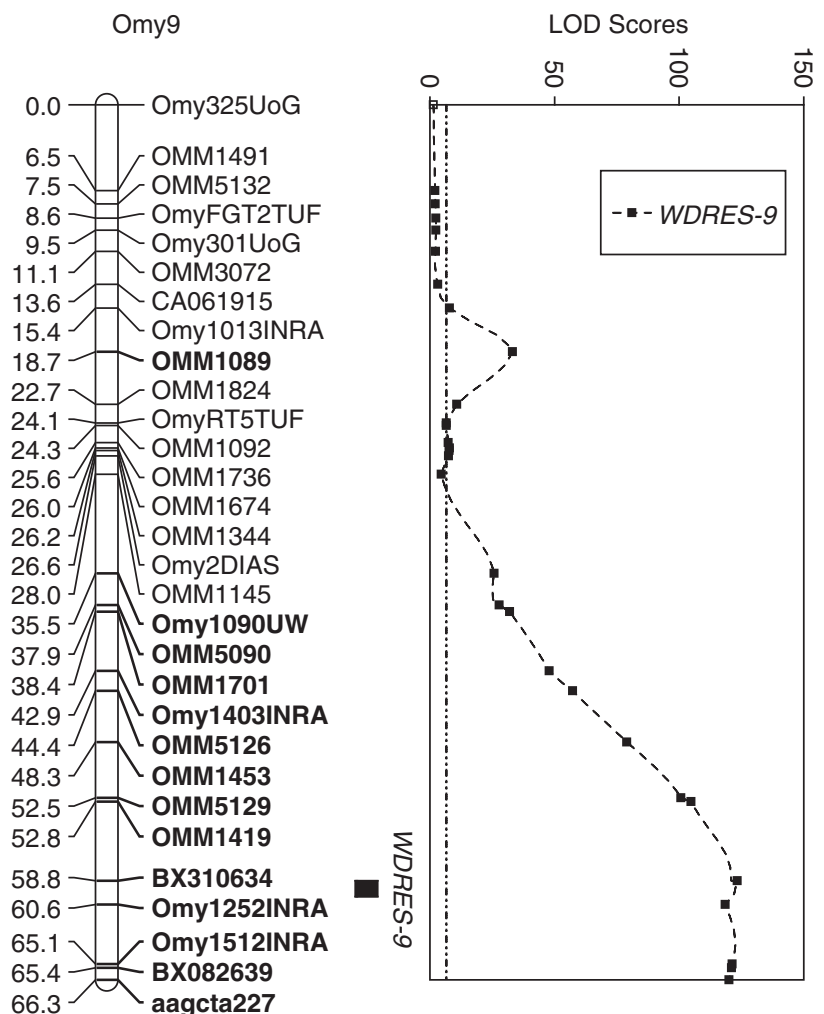

Figure 2 Localization of whirling disease resistance QTL on rainbow trout chromosome Omy9. Map positions and LOD scores are based on combining four outbred $\mathrm{F}_{2}$ mapping families into a single interval mapping QTL analysis using the software MapQTL 6. The combined family $95 \%$ genome-wide LOD significance threshold value is 6.6 (dashed constant line). All markers with LOD scores $>20$ are shown in bold. The QTL (termed WDRES-9) has a LOD peak of 123.3 and the $95 \%$ confidence interval is a $1.85 \mathrm{cM}$ region including marker $\mathrm{BX} 310634$.

LOD for all four mapping families and when all families were combined into a single IM analysis, the maximum LOD value increased to 123.3 (Figure 2). A total of 14 syntenic markers have LOD values greater than 20. The 2-LOD support interval spans a $1.85 \mathrm{cM}$ segment of the chromosome, which corresponds to approximately $1,698 \mathrm{~kb}$ pairs (Young et al., 1998). The phenotypic variance explained ranged from 49.6 to $85.9 \%$ per family. Using weight and length as covariates neither reduced the residual variance nor altered the position of any LOD peaks and therefore were not included in the reported analyses.

Finally, allelic segregation patterns of marker BX310634 were examined. Allele 202, corresponding to a 202 base pair PCR product, was segregating in all four 
mapping families (dam or sire of $\mathrm{F}_{2}$ generation) and was present in at least one copy for $100 \%$ of the completely resistant individuals compared with $34 \%$ of the most susceptible individuals. Comparing homozygosity frequencies of allele 202 was quite dramatic, with $83 \%$ of the completely resistant individuals being homozygous (that is, 202/202) in contrast with none of the $20 \%$ most susceptible individuals. All pure Hofer grandparents of the $\mathrm{F}_{2}$ generation were fixed for allele 202 (homozygous), whereas only two CRR grandparents had allele 202, both in the heterozygous state.

\section{Discussion}

We provide the first evidence for a major QTL (WDRES9) influencing resistance to whirling disease on chromosome Omy9 of O. mykiss. A previous broad-sense heritability $\left(H^{2}\right)$ estimate for $M$. cerebralis pathogen load, using full-sib analysis of $\mathrm{F}_{2}$ CRR $X$ Hofer crosses, estimated that $H^{2}=0.34 \pm 0.21$ (Fetherman, 2008). Although heritability estimates are specific to a particular population in a particular environment, this may indicate that the identified QTL region is capable of explaining up to $100 \%$ of the genetic variance for the four mapped families.

Both parametric and non-parametric analyses provide strong support for the significance of the WDRES-9 QTL, with $P$-values of 0.0001 and LOD scores from 11.6 to 63.1 depending on the family. Figure 2 displays a second smaller peak corresponding to marker OMM1089. This marker appears significant by both $\mathrm{K}-\mathrm{W}$ and IM, but we do not believe that it signifies a second QTL region on Omy9. There is discrepancy regarding its position on the different families' genetic maps (Supplementary Table 1), with two of the four positioning OMM1089 much closer to the terminal end of the genetic map containing the large LOD peak. Existing published O. mykiss genetic maps also position OMM1089 much closer to this terminal end and it is likely that the marker is simply mispositioned in the combined family map and the higher LOD value is because of closer proximity to the WDRES-9 QTL. The $1.85 \mathrm{cM}$ QTL support interval is quite narrow and should be considered a rough approximation, given the extremely large QTL effect size and low recombination rate found in rainbow trout males.

The identification of a single major QTL for whirling disease resistance has important implications for understanding the genetic underpinnings of this phenotype. Our results suggest that a single locus might be responsible for the resistance of Hofer strain to whirling disease, although we cannot exclude the possibility that multiple resistance loci are present within the currently identified QTL region. Our results are consistent with the observed bimodal phenotypic distributions, which suggest the involvement of a limited number of resistance loci for these mapping families. The large prevalence of completely resistant individuals homozygous for allele 202 at BX310634 (83\%) suggests that this QTL region has an additive effect on the whirling disease resistance phenotype.

A global gene expression microarray study previously identified the Metallothionein $B($ Met $B)$ gene as a candidate for involvement in whirling disease resistance, with the Hofer strain significantly upregulating Met $B$ expression following $M$. cerebralis exposure when compared with a susceptible strain of rainbow trout (Baerwald et al., 2008). This gene has been mapped to chromosome Omy2 (Phillips et al., 2006) and is therefore not underlying the detected QTL region of Omy9. It is possible that Met $B$ is directly influencing the whirling disease phenotype but not in Family 1, which was the only family originally scanned across all chromosomes for marker/phenotype linkage. Additionally, perhaps marker coverage near the Met $B$ gene was not sufficient. An approximate $33 \mathrm{cM}$ region of Omy2, in which Met $B$ is positioned, is without marker coverage in our study, which is based on a published rainbow trout genetic map (Guyomard et al., 2006). Future mapping studies should concentrate more markers near Met $B$ to aid in determining whether this gene is directly involved in whirling disease resistance or simply part of a pathway implicated in resistance and not directly affecting the phenotype itself.

Interestingly, a separate genetic mapping study of rainbow trout resistance to a second myxosporean parasite, Ceratomyxa shasta, also found a significant QTL region on Omy9 (Nichols et al., 2003). It is unlikely, however, that a single gene is causing resistance to both of these parasites given that salmonid strains resistant to C. shasta are susceptible to $M$. cerebralis (Hedrick et al., 2001). Another salmonid disease that has mapped to the O. mykiss Omy9 homolog in Atlantic salmon is infectious salmon anemia (Moen et al., 2007). Therefore, it is possible that this chromosome is enriched for salmonid disease resistance genes, although without a sequenced genome, this is highly speculative.

Both fish age and size were found to be key factors influencing the severity of whirling disease in experimentally infected rainbow trout (Ryce et al., 2004, 2005). Therefore, rainbow trout growing at faster rates (for example, the Hofer strain) may more rapidly become resistant to both clinical signs of whirling disease and high numbers of myxospores in their skeletal elements. The results from our current study revealed a negative correlation between growth traits and pathogen load (Table 1), supporting the hypothesis that quicker growth rates lead to lower pathogen loads. This correlation, though statistically significant, had substantial variation across individuals based on $R^{2}$-values (Table 1) and we did not detect growth QTL on any region of Omy9 in the course of this study (data not shown). The lack of genetic correlation for these traits does not nullify the hypothesis as there may be a common QTL region for both growth and whirling disease resistance that went undetected in this study. However, given the major effect the discovered QTL region has on the whirling disease phenotype, it is unlikely that growth has a major role in conferring resistance. In addition, sex of the progeny is not correlated to whirling disease resistance and both sires and dams are capable of passing on allele 202 of marker BX310634 on Omy9.

A limitation to all QTL findings is that they are specific to the populations and families analyzed for a given study. It is quite possible that future studies will discover additional QTL regions contributing to the whirling disease phenotype because of genetic variance across strains and individuals. The results presented here, however, demonstrate that a single chromosomal region is capable of explaining a large percentage of the 
phenotypic variation and perhaps all of the additive genetic variation contributing to the whirling disease phenotype in a given family. This finding, along with broad-sense heritability estimates (Fetherman, 2008), lends strong support to the potential success of MAS for this disease. Before initiating MAS, it would be beneficial to further refine the QTL region by increasing marker density around the QTL peak, likely with newly discovered single nucleotide polymorphism markers (Sanchez et al., 2009), and mapping using additional families and successive generations with larger progeny sizes to increase total recombination events. Additionally, to lend support to the widespread relevance of our results, we recommend that other rainbow trout populations that have shown varying levels of disease resistance undergo QTL mapping before conducting MAS. These studies will determine if the WDRES-9 QTL is unique to the Hofer strain and may potentially identify other strain-specific QTL. We caution against ever using MAS for natural salmonid populations given the likely reduction in total genetic diversity and the unforeseen consequences such actions can have in a stochastic environment. Therefore, we recommend MAS exclusively for non-native-introduced and hatchery populations that are unlikely to come into contact with native populations in the wild and only after additional QTL refinement and verification.

The CRR strain, although uniformly susceptible to whirling disease, has shown considerable variance in the pathogen load levels across individuals when reared in a common environment and broad-sense heritability estimates of $M$. cerebralis pathogen load, for the CRR strain are quite high at $0.89 \pm 0.28$ (Fetherman, 2008). Therefore, the strain appears to have a genetic component impacting resistance, albeit likely present at relatively low frequencies. This suggests that under strong selective pressure, this strain may have the potential to increase its overall resistance to whirling disease over time without hybridization to the Hofer strain, which is currently underway. It is unknown whether the CRR grandparent with BX310634's allele 202 contributed to observed resistance in the mapping families or whether resistance was derived solely from the Hofer grandparents. Future work could determine whether allele 202 is highly correlated with lower susceptibility in the CRR strain and, if so, allelic frequency may be quite useful in determining how quickly whirling disease resistance could build in the strain. Additionally, an assessment of the CRR strain's overall genetic diversity should be conducted to ensure genetic drift does not overwhelm selection as the primary evolutionary force. A few wild rainbow trout populations in the US have demonstrated successful comebacks from whirling disease (for example, rainbow trout in Montana's Wounded Man Lake (Miller and Vincent, 2008) and Madison River), highlighting the importance of maintaining genetic diversity in rainbow trout populations. These wild strains may serve as excellent mapping populations to further verify the consistency of the major effect whirling disease QTL discovered on chromosome Omy9.

\section{Conflict of interest}

The authors declare no conflict of interest.

\section{Acknowledgements}

We thank Terry McDowell for $M$. cerebralis exposures and fish rearing, Kaveramma Mukkatira for triactinomyxons isolation, members of the Hedrick and May labs for assistance with tissue dissection and Brian Mahardja and Denise Lin for assistance with genotyping. This study was funded by a postdoctoral fellowship to $\mathrm{M}$ Baerwald from the USDA (NIFA Grant: 2008-35205-18719).

\section{References}

Addinsoft (2009). XLStat version 2009. Available at: http:// www.xlstat.com. Addinsoft Inc.: Paris, France.

Agresti JJ, Seki S, Cnaani A, Poompuang S, Hallerman EM, Umiel $N$ et al. (2000). Breeding new strains of tilapia: development of an artificial center of origin and linkage map based on AFLP and microsatellite loci. Aquaculture 185: 43-56.

Baerwald MR, Welsh AB, Hedrick RP, May B (2008). Discovery of genes implicated in whirling disease infection and resistance in rainbow trout using genome-wide expression profiling. BMC Genomics 9: 11.

Bartholomew JL, Reno PW (2002). Review: the history and dissemination of whirling disease. In: Bartholomew JL, Wilson JC (eds). American Fisheries Society Symposium, Vol. 29: Whirling Disease: Reviews and Current Topics. Bethesda, MD. pp 3-24.

Broman KW (2003). Mapping quantitative trait loci in the case of a spike in the phenotype distribution. Genetics 163: 1169-1175.

Brunelli JP, Wertzler KJ, Sundin K, Thorgaard GH (2008). Y-specific sequences and polymorphisms in rainbow trout and Chinook salmon. Genome 51: 739-748.

Danzmann RG, Cairney M, Davidson WS, Ferguson MM, Gharbi K, Guyomard R et al. (2005). A comparative analysis of the rainbow trout genome with 2 other species of fish (Arctic charr and Atlantic salmon) within the tetraploid derivative Salmonidae family (subfamily: Salmoninae). Genome 48: 1037-1051.

Fetherman E (2008). Heritability of Myxospore Count and The Effects of Myxobolus cerebralis Exposure on The Physiological Performance of Whirling Disease Resistant and Susceptible Strains of Rainbow Trout. Master of Science thesis, Colorado State University: Fort Collins.

Guyomard R, Mauger S, Tabet-Canale K, Martineau S, Genet C, Krieg F et al. (2006). A type I and type II microsatellite linkage map of Rainbow trout (Oncorhynchus mykiss) with presumptive coverage of all chromosome arms. BMC Genomics 7: 13.

Hedrick RP, McDowell TS, Gay M, Marty GD, Georgiadis MP, MacConnell E (1999a). Comparative susceptibility of rainbow trout Oncorhynchus mykiss and brown trout Salmo trutta to Myxobolus cerebralis, the cause of salmonid whirling disease. Dis Aquat Org 37: 173-183.

Hedrick RP, McDowell TS, Marty GD, Fosgate GT, Mukkatira K, Myklebust K et al. (2003). Susceptibility of two strains of rainbow trout (one with suspected resistance to whirling disease) to Myxobolus cerebralis infection. Dis Aquat Org 55: 37-44.

Hedrick RP, McDowell TS, Mukkatira K, Georgiadis MP, MacConnell E (1999b). Susceptibility of selected inland salmonids to experimentally induced infections with $M y x-$ obolus cerebralis, the causative agent of whirling disease. J Aquat Anim Health 11: 330-339.

Hedrick RP, McDowell TS, Mukkatira K, Georgiadis MP, MacConnell E (2001). Salmonids resistant to Ceratomyxa shasta are susceptible to experimentally induced infections with Myxobolus cerebralis. J Aquat Anim Health 13: 35-42.

Kelley GO, Zagmutt-Vergara FJ, Leutenegger CM, Myklebust KA, Adkison MA, McDowell TS et al. (2004). Evaluation of five diagnostic methods for the detection and quantification of Myxobolus cerebralis. J Vet Diagn Invest 16: 202-211. 
Lander ES, Botstein D (1989). Mapping Mendelian factors underlying quantitative traits using Rflp linkage maps. Genetics 121: 185-199.

MacConnell E, Vincent ER (2002). Review: the effects of Myxobolus cerebralis on the salmonid host. In: Bartholomew JL, Wilson JC (eds). American Fisheries Society, Vol. Symposium 29. Bethesda, MD. pp 95-107.

Markiw ME (1991). Whirling disease-earliest susceptible age of rainbow-trout to the triactinomyxid of Myxobolus-Cerebralis. Aquaculture 92: 1-6.

Miller MP, Vincent ER (2008). Rapid natural selection for resistance to an introduced parasite of rainbow trout. Evol Appl 1: 336-341.

Moen T, Sonesson AK, Hayes B, Lien S, Munck H, Meuwissen THE (2007). Mapping of a quantitative trait locus for resistance against infectious salmon anaemia in Atlantic salmon (Salmo Salar): comparing survival analysis with analysis on affected/resistant data. BMC Genet 8: 13.

Nehring RB, Walker PG (1996). Whirling disease in the wild: the new reality in the intermountain west. Fisheries 21: 28-30.

Nichols KM, Bartholomew J, Thorgaard GH (2003). Mapping multiple genetic loci associated with Ceratomyxa shasta resistance in Oncorhynchus mykiss. Dis Aquat Org 56: 145-154.

Phillips RB, Nichols KM, DeKoning JJ, Morasch MR, Keadey KA, Rexroad C et al. (2006). Assignment of rainbow trout linkage groups to specific chromosomes. Genetics 174: 1661-1670.

Rexroad CE, Palti Y, Gahr SA, Vallejo RL (2008). A second generation genetic map for rainbow trout (Oncorhynchus mykiss). BMC Genet 9: 14.

Ryce EKN, Zale AV, MacConnell E (2004). Effects of fish age and development of whirling parasite dose on the disease in rainbow trout. Dis Aquat Org 59: 225-233.

Ryce EKN, Zale AV, MacConnell E, Nelson M (2005). Effects of fish age versus size on the development of whirling disease in rainbow trout. Dis Aquat Org 63: 69-76.

Sakamoto T, Danzmann RG, Gharbi K, Howard P, Ozaki A, Khoo SK et al. (2000). A microsatellite linkage map of rainbow trout (Oncorhynchus mykiss) characterized by large sex-specific differences in recombination rates. Genetics 155: 1331-1345.

Sanchez C, Smith T, Wiedmann R, Vallejo R, Salem M, Yao J et al. (2009). Single nucleotide polymorphism discovery in rainbow trout by deep sequencing of a reduced representation library. BMC Genomics 10: 559.

Schisler GJ, Myklebust KA, Hedrick RP (2006). Inheritance of Myxobolus cerebralis resistance among F1 generation crosses of whirling disease resistant and susceptible rainbow trout strains. I Aquat Anim Health 18: 109-115.

Schuelke M (2000). An economic method for the fluorescent labeling of PCR fragments. Nat Biotechnol 18: 233-234.

Severin VIC, El-Matbouli M (2007). Relative quantification of immune-regulatory genes in two rainbow trout strains, Oncorhynchus mykiss, after exposure to Myxobolus cerebralis, the causative agent of whirling disease. Parasitol Res 101: 1019-1027.

Simpson A (2004). The global invasive species information network: what's in it for you? Bioscience 54: 613-614.

Thorgaard GH (1983). Chromosomal differences among rainbow trout populations. Copeia 1983: 650-662.

Van Ooijen JW (2006). JoinMap 4. Software for the calculation of genetic linkage maps in experimental populations. Kyazma BV: Wageningen, Netherlands.

Van Ooijen JW (2009). MapQTL 6. Software for the mapping of quantitative trait loci in experimental populations of diploid species. Kyazma BV: Wageningen, Netherlands.

Vincent ER (2002). Relative susceptibility of various salmonids to whirling disease with emphasis on rainbow and cutthroat trout. In: Bartholomew JL, Wilson JC (eds). American Fisheries Society, Vol. Whirling disease: Reviews and Current Topics; Symposium 29. Bethesda, MD. pp 109-115.

Voorrips RE (2002). MapChart: software for the graphical presentation of linkage maps and QTLs. J Hered 93: 77-78.

Vos P, Hogers R, Bleeker M, Reijans M, Vandelee T, Hornes M et al. (1995). AFLP: a new technique for DNA fingerprinting. Nucleic Acids Res 23: 4407-4414.

Wagner EJ, Wilson C, Arndt R, Goddard P, Miller M, Hodgson A et al. (2006). Evaluation of disease resistance of the Fish Lake-DeSmet, Wounded Man, and Harrison Lake strains of rainbow irout exposed to Myxobolus cerebralis. J Aquat Anim Health 18: 128-135.

Young WP, Wheeler PA, Coryell VH, Keim P, Thorgaard GH (1998). A detailed linkage map of rainbow trout produced using doubled haploids. Genetics 148: 839-850.

Supplementary Information accompanies the paper on Heredity website (http://www.nature.com/hdy) 